\title{
Factors Determining Youth's Recreational Behaviour and its Effects on Body Mass Index (BMI)
}

\section{Dwi Rizka Zulkia ${ }^{1},{ }^{*}$ Rosilawati Zainol ${ }^{2}$, Norlelawati Zainol ${ }^{3}$, Nikmatul Adha Nordin ${ }^{4}$ \& Faizah Ahmad ${ }^{5}$}

\author{
${ }^{1245}$ Department of Urban and Regional Planning, Faculty of Built Environment, \\ University of Malaya, 50603 Kuala Lumpur, Malaysia \\ ${ }^{3}$ Faculty of Medicine and Health Sciences, Islamic Science University of Malaysia, \\ 71800, Nilai, Negeri Sembilan, Malaysia \\ *rosilawatizai@um.edu.my
}

\begin{abstract}
Youth require recreational activities to enhance their physical and mental health. This study seeks to identify the determinants of youth's recreational behaviour and effects to their body mass index by built environmental factors. A pilot study was carried out to determine the physical activity, the sedentary behaviour, accessibility and safety of recreational park, and its association with youth body weight index. Respondents comprise of 30 youth aged between 15 to 16 years, randomly selected from a few secondary schools in Subang Jaya, Selangor. Physical activity and sedentary behaviour were measured using the Physical Activity Questionnaire for Adolescents (PAQ-A) and the Adolescent Sedentary Activity Questionnaire (ASAQ). Body mass index (BMI) on the other hand, was computed by measuring the height and weight of the respondents. Accessibility and safety of recreational park were also assessed. The findings reveal that almost half of the respondents have a normal BMI, while $33.3 \%$ were severely thin and $20.0 \%$ were overweight and obese. For physical activity, most of the respondents stated that they play futsal on both weekday $(60.0 \%)$ and weekend $(46.7 \%)$. For sedentary behaviour, watching television is the best choice for respondents to spend their leisure time, about $100.0 \%$ on weekday and $86.7 \%$ on weekend. There is a modest relationship between BMI and youth who play futsal. Two factors were identified as the reasons for not going to the park which are lack of playing facilities and perception of safety and crime. This study demonstrates the need of youth to be healthy and physically active by playing sport at the park as their recreational activities. Support in terms of proximity of the parks from their home and the provision of sufficient facilities influence youth's recreational activities.
\end{abstract}

Keywords: recreational park, body mass index (BMI), youth physical activity, sedentary behaviour, accessibility.

\section{INTRODUCTION}

In this globalization era, global media and Information and Communication Technologies (ICT) have advanced and continue to change the world. Youth follow the development of ICT to support their daily activity that can help them to grow and develop themselves in such environment. Youth with skills of using ICT are interested to learn new things in many ways based on their needs. This situation 
has increasingly challenged the traditional forms of socialization with family and community (United Nation, 2004).

It has been found that $87 \%$ of the youth today play internet (Weiss, 2005) representing 21 million youth around the world. The 2005 World Youth Report section on youth in civil society reveals that ICT is progressively being used as a platform to look up for access to education and occupation chances, that promotes efforts to exterminate poverty. Malaysian Youth Index 2011 reveals that the media penetration score by youth is 87.1 for 2011 . This is slightly higher than the one in 2008 with a score of 85.0 and in 2006 with a score of 84.8 (Malaysian Institute for Research in Youth Development, 2011).

Youth have many ways of expressing their recreational behaviour, with or without using technology (United Nation, 2004). Generally, youth of present days have the freedom to indulge in their hobbies, interests or leisure time and rest their busy mind from school work. During the past decade, research on how youth spend their leisure time or out-of-school time has expanded significantly. Most of the recent studies of youth or student indicate the positive associations between participation in out-ofschool or recreational activities and physical well-being, positive self-development, and interpersonal competence (Bartko \& Eccles, 2003; Kassing, 2006; Pittman et al., 2003). Recreational activities for youth can take in various forms ranging from those that require a great amount of energy to lowenergy activities and depends on factors that are able to attract them to the parks (Loukaitou-Sideris, A., \& Sideris, A. (2009). Depending on personalities, lifestyles and gender (Llyod et al., 2008), the recreational activities offer some respite from mundane routine of daily living can be beneficial for physical and mental health.

Recreational behaviour for youth can be classified into physical activity behaviour (active recreation) and sedentary behaviour (passive recreation) (Must \& Tybor, 2005). Passive recreation involves activities such as sitting at a park bench, taking a walk at a riverside, strolling at the beach, watching television, or playing online games. On the other hand, active recreation is about participating in adventure sports or outdoor games. In Malaysia, leisure time for youth can be divided into three categories namely, sports, leisure activities, and clubs and associations. A study carried out by the Ministry of Youth and Sports (2012) suggested that badminton and football are the most preferred sports among the youth, while sports club is the best choice for youth to participate, and entertainment like karaoke, clubbing, watching movies, etc. and recreational activities like picnics, camping, travelling, etc. are the most preferred leisure activities among youth in Malaysia.

Engaging in recreational activities is important for youth at this age of their life to fulfil their primary recreational needs. Some of the primary recreational needs which have been identified include the need for affection, health, ability to socialize with others, creative ability, fun and enjoyment, sense of freedom, sense of humour, new experience and quality of life (Alberta Recreation \& Parks, 2010). In Malaysia, youth must be motivated to take part in any recreational activities which are usually affected by their behavioural patterns such as preferences and needs (Lee, 2003). According to Ajzen (1991), youth desire for recreational activities can be related to the theory of planned behaviour. This theory highlights the relationship between the positive attitudes toward recreation and the societal pressure placed on an individual. Time investment, effort and energy are required for any recreational activities program participation. In addition, internal factors such as injury risk and skill levels and external factors such as weather conditions and accessibility have impacts on individuals' choices. Thus, perceived behavioural control is considered as an important variable (Ajzen, 1991).

In another study related to youth recreational activities, Anderson et al. (2008) found that urban youth prefers indoor activities due to their laziness of movement and the comfortable atmosphere in a room 
or indoor environment as compared to outdoor activities that requires a lot of energy, desire and strong interest in exercising and friends who also have similar interest in sports. Several other factors that cause youth not to play in the park include lack of interest in the activities of the existing parks, lack of time in family activities, and concern about safety in the park (Loukaitou-Sideris \& Sideris, 2009).

Obesity or overweight are two weight categories that can be identified by calculating a Body Mass Index (BMI). Over the years, there is an increasing number of youth classified as being overweight and obese. According to the National Health and Morbidity Survey 2006 (Institute for Public Health, 2008), the prevalence of obesity has increased over the past decade, whereby $15 \%$ of youths age $12-$ 19 years old are overweight and $15 \%$ are obese. Many studies have been carried out to identify the relationship between obesity and overweight with recreational behaviour (Hu et al., 2003; Sallis et al., 2012; Sallis \& Glanz, 2006; Salmon et al., 2000). Recreational activities which involve physical movements may help in controlling obesity, decreasing the risk of disease, boosting the immune system, and increasing life expectancy (Schwarzenegger et al., 2005). A study on youth in Canada demonstrates that increasing physical activity and reducing sedentary behaviour can help in reducing obesity (Goldfield et al., 2007). The Ministry of Health Malaysia (2010) states that one of the causes of youth becoming overweight and obese is low physical activity or not exercising at all. Many researchers state that the prevalence of obesity is associated with environmental changes that promote indoor activities that do not require much energy (Burdette \& Whitaker, 2005; Ewing et al., 2003; Frank et al., 2004; Janssen et al., 2005; Ozdemir \& Yilmaz, 2008; Wolch et al., 2011). In a study on children's recreational behaviour in the United States, Anderson, et al. (2008) reveal that children aged four to eleven who have low level of active play and high screen time fall among older age female ( 9 - 11 years old), non-Hispanic black/ethnicity and have a BMI of z-score $\geq 95$ th percentile. Therefore, children who have high BMI are at risk for growing up as obese adults. Besides low active play and high screen time, environmental factors such as family, school or the surroundings can also lead to obesity (Eisenberg et al., 2007; Misra \& Khurana, 2008).

Built environment provides support to ensure youth leads healthy active lifestyle through the provision of recreational parks or open spaces (Brisbon et al., 2005; Goldfield, et al., 2007; Hinckson et al., 2014; Wolch et al., 2011). Past studies indicate the associations between the built environment and physical activity behaviours, which in turn impact health outcomes (Lee et al., 2008; Rao et al., 2010; Roof \& Oleru, 2008). The design elements of built environment that can promote physical activity include availability, accessibility and safety at recreational parks (Loukaitou-Sideris \& Sideris, 2009; McCormack et al., 2010).

Availability of recreational parks within 500 meters of residential areas plays an important role in promoting physical activity among youth (Maas, et al., 2008). Previous researchers have focused on the link between access to recreation facilities and youth's physical activity. These studies suggest that youth with convenient access to recreational facilities and programs, usually near their homes are more active than those without such access (Sallis, et al., 2012). The nearer the parks from their home, the higher tendency for them to use recreational facilities in the parks. This will lead to more rigorous physical activities (Hoefer et al., 2001). The easy access from homes to the parks and the close proximity may incidentally promote walking which is beneficial to health (Giles-Corti et al., 2005; Giles-Corti \& Donovan, 2002, 2003). This is also supported by Gardsjord et al. (2014) who carried out a review on factors that have effect on youth physical activity and one of the issues highlighted is accessibility to parks.

Previous studies demonstrate that the design of built environment does promote physical activity which positively affects health (Carlson et al., 2012; Giles-Corti \& Donovan, 2003). It is also 
suggested that a 5\% increase in neighbourhood walkability is linked to $32.1 \%$ more minutes devoted to physically active travel and about one-quarter point lower BMI (0.228) (Frank et al., 2006). A study by Rezali et al. (2012) in Kajang District of Selangor State demonstrates a link between overweight and obesity among Malaysian youths with physical activity and body image (Rezali et al., 2012). This further proves that while obesity is seen as an individual health issue, the setting of the environment that we live in may help in mitigating the issues. In this light, the professionals, policymakers and decision-makers in the built environment have roles to play in creating a living environment that is less conducive to weight gain (Noor et al., 2005).

In sum, the recreational behaviour, obesity and built environment are inter-related. Therefore, this study aims to examine additional factors that contribute to the youth recreational behaviour in relation to the built environment criteria. This paper is divided into four main sections, firstly the discussion on the background study on the relationship between youth recreational behaviour, obesity and the built environment, secondly the methodology of the study, thirdly the results, and finally, discussion and conclusion.

\section{METHODOLOGY}

The pilot study was conducted in a selected secondary school in Subang Jaya, Selangor and its main respondents are youth aged fifteen to sixteen years old. Subang Jaya with a population of 708,296 people, is the third largest city in the state of Selangor after Kajang, 795,522 people and Klang, 744,062 people (Department of Statistics, 2010). A survey was carried out from January to February 2013 and it was a cross sectional study. A total of 30 respondents participated in this study. This is the only number of students that were able to take part due to time constraint allowed by the school's administrator.

Data collection was based on questionnaire which consisted of multiple sections with regards to demographic data, accessibility and barriers to the recreational parks, physical activity level, sedentary behaviour level, and body mass index of the respondents. Physical activity and sedentary behaviour sections were measured by the Physical Activity Questionnaire for Adolescents (PAQ-A) (Rosenberg et al., 2008) and The Adolescent Sedentary Activity Questionnaire (ASAQ)(Hardy et al., 2007). Height and weight were measured to compute body mass index (BMI). The BMI is calculated based on the following formula:

$$
\begin{aligned}
& \mathrm{BMI}=\mathrm{x} \mathrm{kg} /\left(\mathrm{y} \mathrm{M}^{*} \mathrm{yM}\right) \\
& \text { where } \mathrm{x}=\text { bodyweight in } \mathrm{Kg} \text { and } \mathrm{y}=\text { height in meter. }
\end{aligned}
$$

Accessibility and safety of recreational park was also assessed. Permission to do the study was obtained from the Ministry of Education Malaysia as well as State Education Department of Selangor. The selected school was informed and permission was granted by the respective school's principal.

The dependent variables include any measure of (overall) recreational activities of various types of physical activity behaviours and sedentary behaviour (i.e. sports, recreation, physical education, television viewing, reading book, playing game online, etc.). These behaviours are examined within a home/family context, school and community and further expressed in terms of duration (in minutes), or frequency (times per week), or intensity.

The independent variable were built environmental factors that include walkable and cyclable neighbourhoods, mode of transportation to parks i.e. public transit, availability of sport facilities, distance of facility from home, barriers to physical activities, safety from the darkness of parks, graffiti, vandalism, dirty, noisy, and crime. Accessibility to the food stalls or places were not included. 
Body mass index as weight status is an outcome of how the built environment factors can affects recreational behaviour among youth.

The data was analysed using SPSS Version 18.0 to produce the statistical data on demographic of respondent, recreational activity profile, crosstab for selected variables, types of built environment factors that can influence recreational activity and obesity in youth. Correlation and relationship data from the questionnaire were also carried out.

\section{RESULTS}

A total of 30 respondents eligible for the study and all of them are from Form 3 students, aged from 15 years old $(86.7 \%)$ and 16 years old $(13.3 \%)$. A total of $56.7 \%$ were girls and the other $43.3 \%$ boys. Majority are Malays (43.3\%) while the rest comprise mainly of Chinese (33.3\%) and Indian (23.3\%), which $63.3 \%$ are residents of Subang Jaya. Half of the respondents have a normal BMI, while $26.7 \%$ were severely thin and $20.0 \%$ were overweight and $3.3 \%$ were obese (Table 1 ).

Table 1: Sociodemographic characteristic of respondents $(\mathrm{n}=30)$

\begin{tabular}{|l|l|c|c|}
\hline Variable & \multicolumn{1}{|c|}{ Items } & $\mathbf{n}$ & \% \\
\hline \multirow{3}{*}{ Gender } & Male & 13 & 43.3 \\
\cline { 2 - 4 } & Female & 17 & 56.7 \\
\hline \multirow{2}{*}{ Age } & 15 years old & 26 & 86.7 \\
\cline { 2 - 4 } & 16 years old & 4 & 13.3 \\
\hline \multirow{3}{*}{ Ethnicity } & Malay & 13 & 43.3 \\
\cline { 2 - 4 } & Chinese & 10 & 33.3 \\
\cline { 2 - 4 } & Indian & 7 & 23.3 \\
\hline \multirow{3}{*}{ Residents } & Subang Jaya & 19 & 63.3 \\
\cline { 2 - 4 } & Others & 8 & 36.7 \\
\hline \multirow{3}{*}{ BMI } & $<18.50$ (thin) & 15 & 26.7 \\
\cline { 2 - 4 } & $18.50-24.99$ (normal) & 6 & 20.0 \\
\cline { 2 - 4 } & $25.00-29.99$ (overweight) & & 3.3 \\
\cline { 2 - 4 } & $30.00-40.00$ (obese) & 1 & \\
\hline
\end{tabular}

Table 2: Accessibility to the park

\begin{tabular}{|l|l|c|c|}
\hline Variables & \multicolumn{1}{|c|}{ Items } & n & \% \\
\hline Distance of park from home & Less than $0.5 \mathrm{~km}$ & 19 & 63.3 \\
\cline { 2 - 4 } & $0.5-1 \mathrm{~km}$ & 6 & 20.0 \\
\cline { 2 - 4 } & $1-2 \mathrm{~km}$ & 4 & 13.3 \\
\cline { 2 - 4 } & More than 2 km & 1 & 3.3 \\
\hline \multirow{4}{*}{$\begin{array}{c}\text { Choices of transportation to } \\
\text { the park }\end{array}$} & Walk & 24 & 80.0 \\
\cline { 2 - 4 } & Bicycle & 10 & 33.3 \\
\cline { 2 - 4 } & Skateboard & 4 & 3.3 \\
\cline { 2 - 4 } & Drive motorized vehicles & 6 & 13.3 \\
\cline { 2 - 4 } & Ride with friends/parent & & 0 \\
\cline { 2 - 4 } & Bus/transit & & 0 \\
\hline
\end{tabular}

The information about accessibility to the park is shown in Table 2. Respondents stated that they have parks near from their home, less than $0.5 \mathrm{~km}$. Most of the respondents walk to the park $(80.0 \%)$, as compared to those who cycle or ride motorized vehicle.

In Subang Jaya, there are several shopping malls, parks and indoor sport centre where youth can hang out or play. The study shows that $63.3 \%$ of respondents went to the shopping complex such as Sunway Pyramid, Subang Parade and Summit and $33.3 \%$ went to the nearest park from home. The primary 
reasons for the respondents to use the park were playing sports $(66.7 \%)$, followed by meeting friends $(60.0 \%)$ and enjoying the nature or outdoor environment $(56.7 \%)$.

Table 3 highlights the reasons for the respondents going to the parks. Most of the respondents state that they are able to go to the park because they know the location of the park, which is near their homes. However, the respondents' main reason for not going to the parks is due to insufficient recreational and sport facilities such as limited access to futsal court, street soccer court, basketball court, and skateboard court and football field since these facilities can only accommodate a few numbers of players. This is followed by not interested in going and lack of organized activities or programs that they can get themselves involved with.

Table 3: Reasons of not going to the park

\begin{tabular}{|l|l|c|c|}
\hline No & \multicolumn{1}{|c|}{ Situation } & Mean & $\mathbf{1 S D}$ \\
\hline a. & Insufficient recreational and sport facilities & 3.83 & 2.183 \\
\hline b. & Not interested & 3.47 & 2.432 \\
\hline c. & Lack of organized activities or programs for youth & 3.23 & 2.300 \\
\hline d. & Do not have time & 2.63 & 1.810 \\
\hline e. & Too many people at the park & 2.37 & 1.542 \\
\hline f. & Unavailability of public transport & 2.13 & 2.193 \\
\hline g. & No sidewalks or bicycle lanes & 2.03 & 2.059 \\
\hline h. & Too far & 2.00 & 2.084 \\
\hline i. & Heavy traffic & 1.93 & 1.946 \\
\hline j. & Do not know the location of park & 1.77 & 1.716 \\
\hline \multirow{2}{*}{ *1=strongly disagree, 7= strongly agree } & \\
\hline
\end{tabular}

Table 4 summarizes the safety of youth in the park. The findings reveal that respondents feel safe from bullying activities but they do not feel safe from crime. Some of them said that they saw robbers or gangster. Therefore, most parents do not allow their children to go to the park alone. Moreover, the study reveals that the park does not have good lighting.

Table 4: Safety of youth in the park

\begin{tabular}{|l|l|c|c|}
\hline No & \multicolumn{1}{|c|}{ Situation } & Mean & $\mathbf{1 S D}$ \\
\hline a. & It is not safe because of crime (strangers, gangs, drugs, stray animals) & 3.20 & 2.427 \\
\hline b. & It does not have good lighting & 2.80 & 2.235 \\
\hline c. & There are vandalism (e.g. damaged signs, broken bench, etc) & 2.60 & 2.238 \\
\hline d. & Dirty (e.g. noticeable amounts of trash, broken glass, etc) & 2.43 & 2.112 \\
\hline e. & It is near to a main road & 2.30 & 1.915 \\
\hline f. & $\begin{array}{l}\text { There are graffiti (e.g. markings or paintings that reduce the visual quality } \\
\text { of the area) }\end{array}$ & 1.97 & 1.810 \\
\hline g. & Noisy (e.g. noticeable sounds that are unpleasant or annoying) & 1.67 & 1.322 \\
\hline h. & I get bullied, teased, harassed & 1.43 & 1.305 \\
\hline
\end{tabular}

Table 5 shows the number of respondents that do physical activity in both weekday and weekend by gender and by time spent on each physical activity. For physical activity, most of the respondents state that they play futsal on both weekdays $(60.0 \%)$ and weekend $(46.7 \%)$. Males engage more on playing futsal and basketball than females, while females engage more in badminton and jogging. The findings also highlight that youth in Subang Jaya spent more time in physical activity on weekends as compared to weekdays. 
Table 5: Physical activity in both weekday and weekend by gender and by time spent

\begin{tabular}{|c|l|c|c|c|c|c|c|}
\hline \multirow{2}{*}{ Time } & \multirow{2}{*}{ Physical Activities } & \multicolumn{2}{|c|}{ Frequency } & \multicolumn{2}{c|}{ Gender } & \multicolumn{2}{c|}{ Time Spent } \\
\cline { 3 - 8 } & & $\mathbf{n}$ & Percent & Male & Female & Mean & $\mathbf{\pm S D}$ \\
\hline Weekday & Futsal & 18 & 60.0 & 13 & 5 & 4.07 & 2.490 \\
\hline & Basketball & 15 & 50.0 & 6 & 9 & 4.57 & 2.569 \\
\hline & Badminton & 17 & 56.7 & 7 & 10 & 4.60 & 2.283 \\
\hline & Jogging & 12 & 40.0 & 6 & 6 & 5.17 & 2.379 \\
\hline Weekend & Futsal & 14 & 46.7 & 12 & 2 & 4.70 & 2.548 \\
\hline & Basketball & 5 & 16.7 & 4 & 1 & 6.27 & 1.701 \\
\hline & Badminton & 11 & 36.7 & 5 & 6 & 5.53 & 2.097 \\
\hline & Jogging & 9 & 30.0 & 2 & 7 & 5.83 & 1.859 \\
\hline
\end{tabular}

The findings on sedentary behaviour in both weekdays and weekends by gender and by time spent on each activity are shown in Table 6 . For sedentary behaviour, watching television is the top choice for respondents to spend their leisure time, about $100.0 \%$ on weekdays and $86.7 \%$ on weekends. Females engage more on sedentary behaviour than males.

Table 6: Sedentary behaviours in both weekday and weekend by gender and by time spent

\begin{tabular}{|c|l|c|c|c|c|c|c|}
\hline Time & \multirow{2}{*}{ Sedentary Behaviours } & \multicolumn{2}{|c|}{ Frequency } & \multicolumn{2}{c|}{ Gender } & \multicolumn{2}{c|}{ Time Spent } \\
\cline { 3 - 8 } & & $\mathbf{n}$ & Percent & Male & Female & Mean & $\mathbf{\pm S D}$ \\
\hline Weekday & Playing Computer & 24 & 80.0 & 10 & 14 & 1.20 & 0.407 \\
\hline & Watching Television & 30 & 100.0 & 13 & 17 & 1.00 & 0.000 \\
\hline & Reading for fun & 21 & 70.0 & 7 & 14 & 1.30 & 0.466 \\
\hline & Travelling & 7 & 23.3 & 3 & 4 & 1.77 & 0.430 \\
\hline Weekend & Playing Computer & 22 & 73.3 & 8 & 14 & 1.27 & 0.450 \\
\hline & Watching Television & 26 & 86.7 & 11 & 15 & 1.13 & 0.346 \\
\hline & Reading for fun & 19 & 63.3 & 5 & 14 & 1.37 & 0.490 \\
\hline & Travelling & 21 & 70.0 & 9 & 12 & 1.30 & 0.466 \\
\hline
\end{tabular}

Table 7: Correlation between BMI and physical activity

\begin{tabular}{|c|c|c|c|c|c|c|c|}
\hline & \multirow{2}{*}{\multicolumn{4}{|c|}{ BMI }} & \multirow{2}{*}{$\begin{array}{c}\text { Pearson's } \\
\text { R } \\
\end{array}$} & \multirow{2}{*}{ Sig. (2-tailed) } \\
\hline \multicolumn{2}{|c|}{ Recreational Activities } & & & & & & \\
\hline Weekday & Basketball & $\begin{array}{c}<\mathbf{1 8 . 5 0} \\
3\end{array}$ & $\begin{array}{c}\mathbf{1 8 . 5 0}- \\
\mathbf{2 4 . 9 9} \\
8\end{array}$ & $\begin{array}{c}25.00- \\
29.99 \\
3 \\
\end{array}$ & $\begin{array}{c}\text { 30.00- } \\
\mathbf{4 0 . 0 0} \\
1\end{array}$ & -0.172 & 0.363 \\
\hline & Futsal & 6 & 5 & 1 & 0 & $0 .-439^{*}$ & 0.015 \\
\hline & Badminton & 6 & 8 & 3 & 0 & 0.261 & 0.164 \\
\hline & Jogging & 6 & 8 & 4 & 0 & 0.176 & 0.353 \\
\hline Weekend & Basketball & 2 & 1 & 2 & 0 & 0.000 & 1.000 \\
\hline & Futsal & 5 & 4 & 0 & 0 & -0.470 ** & 0.009 \\
\hline & Badminton & 4 & 5 & 2 & 0 & 0.179 & 0.345 \\
\hline & Jogging & 4 & 6 & 3 & 1 & -0.086 & 0.650 \\
\hline
\end{tabular}

*. Correlation is significant at the 0.05 level (2-tailed).

**. Correlation is significant at the 0.01 level (2-tailed).

The findings reveal a significant relationships between respondent's BMI and their physical activity as shown in Table 7 where there is a modest relationship between BMI and youth who played futsal. The significance level is .009, which indicates moderate associations between playing futsal and BMI level. The increase frequency of playing futsal will result in the decrease of BMI. 


\section{DISCUSSION AND CONCLUSION}

Findings from the survey suggest that futsal is the most favoured form of sports among the respondents for both weekdays and weekends, as found in a study by the Ministry of Youth and Sports Malaysia in 2010. Another important finding is that, there is a statistically significant relationship between respondent's BMI and their physical activity. The relationship is highly significant and the sign is negative, which means that BMI decreases as the physical activity increases and vice versa. This shows that when youth are physically active, their BMI is reduced. This will result in reduction of overweight and obesity issues (Goldfield, et al., 2007).

In terms of sedentary behaviour, this study demonstrates that youth spent most of their leisure time watching television and playing computer. It is more prevalent among females. Youth spent more time on both activities during weekdays and weekends. Youth also prefer reading. These activities require minimal energy and can lead to overweight and obesity (Anderson, et al., 2008). Thus, promoting physical activities needs to be enhanced among female youth.

Results of this study reveal that most of youths have normal BMI $(63.3 \%)$ and the remaining is either too thin $(26.7 \%)$ or overweight and obese $(23.3 \%)$. About $63.3 \%$ of youth have access to recreational parks which are located within 500 meters of their homes and most of them either walk or cycle to these parks. However, despite the high accessibility to parks, this study discovered few factors that discourage youth from going to the parks such as insufficient recreational and sports facilities, lack of interest and lack of activities at the parks. As mentioned earlier, this study aims to examine additional factors that contribute to the youth recreational behaviour in relation to the built environment criteria. Therefore, one of the results of this study shows that the provision of sufficient recreational and sport facilities at the park that meet youth's needs and expectation will attract youth to go to the parks more frequently. This support the findings from a previous study which found that the availability of certain park facilities play an important role in promoting physical activity (Atkinson et al., 2005; McCormack, et al., 2010). Recreation facilities for youth are important to support physical activities in the park (Moody et al., 2004). In addition, provision of recreational facilities within walking distance will lead to improved health quality (Giles-Corti, et al., 2005).

Safety is another issue highlighted in this study. The presence of stray animals, gangs and strangers may keep youth away from the parks. Based on the observations, some parks suffer from inadequate lighting. These factors further discourage youth from going to the parks. Therefore, providing suitable and sufficient recreational facilities and activities at the parks should be packaged with sufficient safety measures (Loukaitou-Sideris \& Sideris, 2009; McCormack, et al., 2010).

In conclusion, physical activity among youth also influences youth health. As most of the factors that influence physical activity among youth are modifiable factors, it is important that these factors be identified and dealt with at the early stage of youth's life. Youth need to be healthy and physically active by playing sport at the park as their recreational activities. Factors such as the proximity of parks from their home and the provision of sufficient and suitable facilities affect youth's recreational activities. Thus, the challenge is to understand the relationship between the built environment and youth behaviour and then develop models that can predict the environmental conditions that will encourage youth to be more physically active. Such models can assist planners in the design and management of the built environment so as to promote physical activity by providing diverse opportunities for physical activities, ensuring equitable distribution of recreational facilities and emphasizing physical activity over other programs. Further studies are required to determine how the built environment affects youth recreational activity and obesity so as to improve the development of a more suitable and relevance policy to link recreational activity and obesity. 


\section{REFERENCES}

Ajzen, I. (1991). The theory of planned behavior. Organizational Behavior and Human Decision Processes, 50, 179-211.

Alberta Recreation \& Parks. (2010). Simply put, recreation and parks are essential to life. Retrieved 30 September, 2010, from http://arpaonline.ca/

Anderson, S., Economos, C., \& Must, A. (2008). Active play and screen time in US children aged 4 to 11 years in relation to sociodemographic and weight status characteristics: A nationally representative cross-sectional analysis. BMC Public Health, 8(1), 366.

Atkinson, J. L., Sallis, J. F., Saelens, B. E., Cain, K. L., \& Black, J. B. (2005). The association of neighborhood design and recreational environments with physical activity. Am J Health Promot, 19(4), 304-309.

Bartko, W. T., \& Eccles, J. S. (2003). Adolescent participation in structured and unstructured activities: A person-oriented analysis. Journal of Youth and Adolescence, 32(4), 233-241. doi: 10.1023/A:1023056425648

Brisbon, N., Plumb, J., Brawer, R., \& Paxman, D. (2005). The asthma and obesity epidemics: The role played by the built environment-A public health perspective. American Academy of Allergy, Asthma and Immunology, 115(5). doi: 10.1016/j.jaci.2005.02.020

Burdette, H. L., \& Whitaker, R. C. (2005). A national study of neighborhood safety, outdoor play, television viewing, and obesity in preschool children. Pediatrics, 116, 657-662.

Carlson, C., Aytur, S., Gardner, K., \& Rogers, S. (2012). Complexity in built environment, health, and destination walking: A neighborhood-scale analysis. Journal of Urban Health, 89(2). doi:10.1007/s11524-011-9652-8

Department of Statistics. (2010). Population distribution by local authority areas and mukims. Putrajaya: Malaysian Department of Statistics.

Eisenberg, J., Radunovich, H. L., \& Brennan, M. A. (2007). Understanding youth and adolescent overweight and obesity: Resources for families and communities. University of Florida.

Ewing, R., Schmid, T., Killingsworth, R., Zlot, A., \& Raudenbush, S. (2003). Relationship between urban sprawl and physical activity, obesity, and morbidity. Am. J. Health Promot, 18, 47-57.

Frank, L. D., Andresen, M. A., \& Schmid, T. L. (2004). Obesity relationships with community design, physical activity, and time spent in cars. American Journal of Preventive Medicine, 27(2), 8796. doi: 10.1016/j.amepre.2004.04.011

Frank, L. D., Sallis, J. F., Conway, T. L., Chapman, J. E., Saelens, B. E., \& Bachman, W. (2006). Many pathways from land use to health: Associations between neighborhood walkability and active transportation, body mass index, and air quality. Journal of the American Planning Association, 72(1), 75-87. doi: 10.1080/01944360608976725

Gardsjord, H. S., Tveit, M. S., \& Nordh, H. (2014). Promoting youth's physical activity through park design: Linking theory and practice in a public health perspective. Landscape Research, 39(1), 70-81. doi: 10.1080/01426397.2013.793764

Giles-Corti, B., Broomhall, M. H., Knuiman, M., Collins, C., Douglas, K., Ng, K., Lange, A., \& Donovan, R. J. (2005). Increasing walking: How important is distance to, attractiveness, and size of public open space? American Journal of Preventive Medicine, 28(2, Supplement 2), 169-176.

Giles-Corti, B., \& Donovan, R. J. (2002). The relative influence of individual, social and physical environment determinants of physical activity. Social Science \& Medicine, 54(12), $1793-$ 1812.

Giles-Corti, B., \& Donovan, R. J. (2003). Relative influences of individual, social environmental, and physical environmental correlates of walking. American Journal of Public Health, 93(9), 1583-1589. doi: 10.2105/ajph.93.9.1583 
Goldfield, G., Mallory, R., Parker, T., Cunningham, T., Legg, C., Lumb, A., Parker, K., Prud'homme, D., \& Adamo, K.B. (2007). Effects of modifying physical activity and sedentary behavior on psychosocial adjustment in overweight/obese children. J Pediatr Psychol, 32, 783 - 793.

Hardy, L. L., Booth, M. L., \& Okely, A. D. (2007). The reliability of the Adolescent Sedentary Activity Questionnaire (ASAQ). Prev Med, 45(1), 71-74. doi: S0091-7435(07)00143-0

Hinckson, E. A., Duncan, S., Oliver, M., Mavoa, S., Cerin, E., Badland, H., Stewart, T., Ivory, V., McPhee, J., \& Schofield, G. (2014). Built environment and physical activity in New Zealand adolescents: A protocol for a cross-sectional study. BMJ Open, 4. doi: 10.1136/bmjopen2013-004475

Hoefer, W. R., McKenzie, T. L., Sallis, J. F., Marshall, S. J., \& Conway, T. L. (2001). Parental provision of transportation for adolescent physical activity. Am J Prev Med., 21(1), 48-51. doi: S0749379701003142

Hu, F. B., Li, T. Y., Colditz, G. A., Willett, W. C., \& Manson, J. E. (2003). Television watching and other sedentary behaviors in relation to risk of obesity and type 2 diabetes mellitus in women. The Journal of the American Medical Association, 289(14), 1785-1791. doi: 10.1001/jama.289.14.1785

Institute for Public Health (2008). The third national health and morbidity survey (NHMS III) 2006, Ministry of Health, Malaysia.

Janssen, I., Katzmarzyk, P., Boyce, W., Vereecken, C., Mulvihill, C., Roberts, C., Currie,C., \& Pickett, W. (2005). Comparison of overweight and obesity prevalence in school-aged youth from 34 countries and their relationships with physical activity and dietary patterns. Obesity Reviews, 6, 123 - 132.

Kassing, G. (Ed.). (2006). Introduction to Recreation and Leisure. Human Kinetics, Inc.

Lee, K. M. (2003). Motives and preferences for participation in outdoor recreation among members of selected youth recreation associations: An exploratory study. Master, Universiti Putra Malaysia.

Lee, V., Mikkelsen, L., Srikantharajah, J., \& Cohen, L. (2008). Strategies for enhancing the built environment to support healthy eating and active living, 2012. Retrieved from http://www.calendow.org/uploadedFiles/Publications/Publications_Stories/builtenvironment .pdf

Lloyd, K., Burden, J., \& Kiewa, J. (2008). Young girls and urban parks: Planning for transition through adolescence. Journal of Park and Recreation Administration, [S1], 26(3).

Loukaitou-Sideris, A., \& Sideris, A. (2009). What brings children to the park? Analysis and measurement of the variables affecting children's use of parks. Journal of the American Planning Association, 76(1), 89-107. doi: 10.1080/01944360903418338

Malaysian Institute for Research in Youth Development. (2011). Malaysian youth index Retrieved January 1, 2014, from http://www.ippbm.gov.my/v3-en/index.php/profile/aboutippbm.html?id=267

Maas, J., Verheij, R.A., Spreeuwenberg, P., \& Groenewegen, P.P. (2008) Physical activity as a possible mechanism behind the relationship between green space and health: A multilevel analysis, BMC Public Health, 8:206

McCormack, G. R., Rock, M., Toohey, A. M., \& Hignell, D. (2010). Characteristics of urban parks associated with park use and physical activity: A review of qualitative research. Health \& Place, 16(4), 712-726.

Ministry of Health, Malaysia (2010). National Strategic Plan for Non-Communicable Disease (NSPNCD). Ministry of Health: Kuala Lumpur.

Ministry of Youth and Sports. (2012). Official portal of the ministry of youth and sports Retrieved September 30, 2012, from http://www.kbs.gov.my/

Misra, A., \& Khurana, L. (2008). Obesity and the metabolic syndrome in developing countries. J Clin Endocrinol Metab, 93(11 Suppl 1), S9-30. doi: 10.1210/jc.2008-1595 
Moody, J. S., Prochaska, J. J., Sallis, J. F., McKenzie, T. L., Brown, M., \& Conway, T. L. (2004). Viability of parks and recreation centers as sites for youth physical activity promotion. Health Promot Pract, 5(4), 438-443. doi: 10.1177/1524839903258222

Must, A., \& Tybor, D. (2005). Physical activity and sedentary behavior: A review of longitudinal studies of weight and adiposity in youth. International Journal of Obesity, 29, S84 - S96.

Noor, M. I., Koon, P. B., \& Hashim, Z. (2005). Strategy for the Prevention of Obesity-Malaysia: Universiti Kebangsaan Malaysia.

Ozdemir, A., \& Yilmaz, O. (2008). Assessment of outdoor school environments and physical activity in Ankara's primary schools. Journal of Environmental Psychology, 28, 287-300.

Pittman, K., Irby, M., Tolman, J., Yohalem, N., \& Ferber, T. (2003). Preventing problems, promoting development, encouraging engagement: Competing priorities or inseparable goals? Washington, DC: The Forum for Youth Investment, Impact Strategies, Inc.

Rao, M., Prasad, S., Adshead, F., \& Tissera, H. (2010). The built environment and health. The Lancet, 370(9593), 1111-1113. doi: http://dx.doi.org/10.1016/S0140-6736(07)61260-4

Rezali, F. W., Chin, Y. S., \& Yusof, B. N. M. (2012). Obesity-related behaviors of Malaysian adolescents: A sample from Kajang district of Selangor state. Nutrition Research and Practice, 6(5), 458-465. doi: http://dx.doi.org/10.4162/nrp.2012.6.5.458

Roof, K., \& Oleru, N. (2008). Public health: Seattle and king county's push for the built environment. Journal of Environmental Health, 71(1).

Rosenberg, D. E., Bull, F. C., Marshall, A. L., Sallis, J. F., \& Bauman, A. E. (2008). Assessment of sedentary behavior with the International Physical Activity Questionnaire. J Phys Act Health, 5 Suppl 1, S30-44.

Sallis, J. F., Floyd, M. F., Rodriguez, D. A., \& Saelens, B. E. (2012). Role of built environments in physical activity, obesity, and cardiovascular disease. Circulation, 125(5), 729-737. doi: 10.1161/CIRCULATIONAHA.110.969022

Sallis, J. F., \& Glanz, K. (2006). The role of built environment in physical activity, eating and obesity in childhood. The future of the Children, 16(1), 89-108. doi: 10.1353/foc.2006.0009

Salmon, J., Bauman, A., Crawford, D., Timperio, A., \& Owen, N. (2000). The association between television viewing and overweight among Australian adults participating in varying levels of leisure-time physical activity. International Journal of Obesity \& Related Metabolic Disorders, 24(5), 600-607.

Schwarzenegger, A., Chrisman, M., \& Coleman, R. (2005). The health and social benefits of recreation: An element of the california outdoor recreation planning program. Sacramento, California: California State Parks.

United Nation. (2004). Rethinking leisure time. World Youth Report 2003. New York: The Department of Economic and Social Affairs of the United Nations Secretariat.

Weiss, D. L. (2005). Youth \& the Internet. Focus on the Family.

Wolch, J., Jerrett, M., Reynolds, K., McConnell, R., Chang, R., Dahmann, N., \& Berhane, K. (2011). Childhood obesity and proximity to urban parks and recreational resources: A longitudinal cohort study. Health Place, 17(1), 207-214. doi: 10.1016/j.healthplace.2010.10.001.

Wolch, J., Jerrett, M., Reynolds, K., McConnell, R., Chang, R., Dahmann, N., Brady, K., Gilliland, F., Su, J.G., \& Berhane, K. (2011). Childhood obesity and proximity to urban parks and recreational resources: a longitudinal cohort study. Health Place, 17(1), 207-214. doi: 10.1016/j.healthplace.2010.10.001. 